RESEARCHARTICLE

\title{
Engineering Motivation Using the Belief-Expectancy-Control Framework
}

\author{
Richard E. Clark ${ }^{1 *}$ and Bror Saxberg ${ }^{2}$ \\ ${ }^{1}$ School of Education, University of Southern California, USA \\ ${ }^{2}$ Chan-Zuckerberg Initiative, USA
}

\begin{abstract}
This article describes a practical approach to diagnosing and solving some of the motivation problems encountered in educational settings using the evidence-based Belief-Expectancy-Control (BEC) Framework. We think of this framework as a "learning engineering" approach, because it integrates and applies a wide array of research results and clinical experience by teachers and instructional designers to guide the solution of a practical problem at scale: how to identify and solve some of the typical motivation problems experienced by teachers and instructional designers serving adolescent and adult students. The framework is based on research stemming from expectancy, value, and control theories of motivation and provides ways to measure the behaviors defining effortbased motivation - starting, persisting, and investing adequate mental effort to succeed. It then describes and demonstrates how to identify four of the main causes of failures to persist or invest adequate effort: student values, self-efficacy, emotions, and attribution errors - and suggests evidence-based strategies for solving each. Our hope is that the BEC framework, will result in a growing practice base and will allow us to personalize effortbased motivation to benefit a greater diversity of students.
\end{abstract}

\section{Keywords}

Motivation, assessment, learning, values, self-efficacy, emotion, attributions, persistence, procrastination, mental effort, group motivation, belief, expectancy, control theory

Citation: Clark, RE and Saxberg B. Engineering Motivation Using the Belief-Expectancy-Control Framework. Interdisciplinary Education and Psychology. 2018; 2(1):4.

Received: October 1, 2017 Accepted: February 20, 2018 Published: March 6, 2018

Copyright: $\odot 2018$ Clark et al. This is an open access article distributed under the terms of the Creative Commons Attribution License, which permits unrestricted use, distribution, and reproduction in any medium, provided the original author and source are credited.

\section{Corresponding author:}

Richard E. Clark, School of Education, University of Southern California, USA E-mail: clark@usc.edu

\section{Introduction}

Much effort in education has focused on how our minds master problems, make decisions, and learn to perform tasks, but is it possible researchers and funding agencies have often not thought as deeply about how to support the breadth of motivation processes necessary to energize learning and performance? We have ended up with many more strategies to support the cognitive elements of learning and instruction than strategies to support the affective and emotional learner motivation to use those strategies.

The most conservative estimates are that for adolescents or adults, academic motivation accounts for about $30 \%$ of learning and transferring or applying what is learned (Colquitt, Lepine, \& Noe, 2000; Lazowski \& Hulleman, 2016) and over 40\% of group performance (Condly, Clark, \& Stolovitch, 2003).Motivation and learning strategies each contribute about the same percentage of impact on learning and transfer of learning (Snow, 1996), so it seems reasonable to suggest motivation deserves considerably more attention than it has received in the past.Any attempt to apply motivation research in practice is limited by:

...the dearth of motivational field studies in education ...relative to correlational / nonexperimental studies and laboratory studies ... Without intervention research, educational researchers are needlessly left on the sidelines when educators ask, 'what should I do now in my classroom based on your research?'(Lazowski \& Hulleman, 2016, p. 628) 
The goal of this discussion is to provide support to teachers and instructional designers by drawing on the motivation problems they report encountering and focusing on the results of existing reviews of field and laboratory studies of effort-based motivation for adolescents and adults. It does not cover the motivational problems experienced by younger children (see for example, Heckhausen \& Schultz, 1995) and is less concerned with research on the characteristics of intrinsically motivated, curious, mastery oriented and effectively selfregulated students (Zimmerman, 2008) or research on the motivational benefits of autonomy (Ryan \& Deci, 2006), and the current versions of intrinsic drive theory (Hull, 1943).Instead, it outlines a tentative framework for identifying and attempting to solve a number of the common, motivation-based learning difficulties students and teachers face in the classroom and online. To accomplish this goal, the framework draws on research and clinical experience to apply attribution (Graham \& Weiner, 1996; Weiner, 1986, 2004), goal orientation (Locke \& Latham, 2002), expectancy-value (Eccles \& Wigfield, 2002) and social-cognitive theories (Bandura, 1997, 2006; Dweck, 2006; Harackiewicz, Barron, Pintrich, Elliot, \& Thrash, 2002; Zimmerman, 2000) emphasizing the effort and persistence issues encountered in authentic, diverse educational environments (for example, Appleton, Christenson, \& Furlong, 2008; Center on Education Policy, 2012; Clark, 2003, 2005, 2006a; Pintrich, 2003).

The BEC Framework is based on evidence from a variety of field studies, well-designed experiments, and research reviews spread over many years suggesting student beliefs about themselves and their learning goals influence expectations about what they are able to control which, in turn, helps us to determine whether their learning difficulties are motivationally based (Bandura, 1997; Bandura \& Schunk, 1981; Clark, 1999; Clark, Howard, \& Early, 2006b; Dweck, 2006; Eccles \& Wigfield, 2002; Elliot, Dweck, \& Yeager, 2018; Heckhausen \& Schultz, 1995; Perkrun, 2006; Plaks, Grant, \& Dweck, 2005; Reynolds, 2003; Salomon, 1983; Schunk, Meece, \& Pintrich, 2014; Shell \& Husman, 2008; Weiner, 1986).Evidence from this research suggested ways to identify the contributions of motivation to learning problems by analyzing the beliefs and expectations of unmotivated learners about how much control their persistence and effort can exercise over learning goals. The problems and solutions described in the BEC framework are those appearing to occur in many instructional contexts. It provides suggestions for different interventions to pursue in order to identify motivation-based learning problems and bring unmotivated learners back to persistent and effortful learning. It does not provide advice about learning problems that may be caused by teaching method issues such as inadequate students' prior knowledge to benefit from instruction or a lack of sufficient guidance or practice to support new learning.

\section{What is Motivation?}

A useful definition of motivation for practice contexts is as a cognitive and affective process influencing whether people start a learning task, persist at it once started, and invest adequate mental effort to succeed (Clark, 1999; Clark et al., 2006b; Condly, 1999; Pintrich \& Schunk, 2002; Schunk et al., 2014).Provided students are able to achieve a goal, receive adequate instruction (and are not prevented by forces outside of their influence), we can assume they are adequately motivated when they start far enough ahead to succeed and once started, persist by working consistently even when faced with appealing distractions, while investing enough mental effort to succeed at even the most challenging tasks (Pintrich \& Schunk, 2002; Schunk et al., 2014).When a lack of motivation can be said to be the cause of failures to learn or solve problems, students have either not given a task adequate mental effort and/or have procrastinated to the point where they either fail or perform far below their potential.

\section{What Goes Wrong with Motivation?}

While many different factors have been suggested as the cause of motivation problems, it is useful to think of many of them as related to one of four factors at the heart of the BEC framework. Each of the four factors and its impact on starting, persisting, and mental effort will be introduced and briefly described. After an introduction to each of the factors, the article will turn to a more detailed discussion of how to collect data, assess problems, and then choose interventions to solve motivation problems using the four factors.

Each of the following factors is presumed to influence learner beliefs and expectancies about the control they can exercise over learning goals:

$$
\begin{array}{ll}
\text { - } & \text { Values } \\
\text { - Self-efficacy }
\end{array}
$$


- Emotions

- $\quad$ Attribution Errors

Values: Eccles and Wigfield (2002) have suggested that value is most often the first issue students consider when faced with a learning goal. The personal value an individual or group attributes to the achievement of a learning goal influences their decisions about starting or persisting at the task (Eccles \& Wigfield, 2002; Wigfield \& Cambria, 2010).Students tend to start and persist at what they believe to be the most important, useful, interesting, or beneficial goals. Teachers and instructional materials often give students reasons for tackling an educational goal, yet those reasons may reflect only the teacher's background and value system but may not influence students who have different family, identity, and cultural experiences. Believing our students are "like us" in what they value may be one of the contributing causes of this motivation problem. Finding out what individual students value most themselves and attaching those values to important educational tasks and learning goals is the key to encouraging students to engage in a learning task and persist until finished (Wigfield \& Cambria, 2010). This may involve encouraging students to reframe or modify their values in order to achieve goals most important to them.

Even when we value a learning outcome, other beliefs about what we can control may impede our motivation. For example, our sense of self-efficacy at the goal or task.

Self-efficacy: Our beliefs about our capability to succeed at a specific learning goal has been found to influence our expectations about the likelihood we will succeed and influences our decision to persist and how much effort we will invest (Bandura, 1979, 1997, 2006). Students can value a task yet have mistaken expectations about their chances to succeed at it. Both under- and over-confident expectations damage motivation. For example, students may expect they will fail because "I can't do math," or minority students who are hindered by the stereotype belief/distraction that "people with my cultural or racial identity do poorly at this kind of test" may be reluctant to challenge themselves (C. M. Steele, 1997, 2003).

Similarly, students who mistakenly and overconfidently believe they already know how to achieve a challenging task or solve a difficult problem (perhaps a bookkeeper taking a finance course for an MBA) will delay starting and see no reason to learn new strategies for handling the task (Clark et al., 2006b).Overconfident students are a special challenge to motivate because of their inaccurate belief they have adequate prior knowledge needed to learn and so when they fail they most often project the blame externally to teachers, tests, or other events (Miller \& Geraci, 2011; Moore \& Healy, 2008).

Values and self-efficacy often interact in problematic ways. When students with low selfefficacy have high value for a task they most often procrastinate and are more likely to report having cheated (Lee, Bong, \& Kim, 2014).

Self-efficacy judgments may change as students experience different kinds of challenges over time in a course or an assigned project. Handling efficacy issues requires the use of effective strategies for assessing efficacy over time and using a number of research-tested strategies to help students to adjust their self-efficacy expectations. As we shall see, most evidence-based strategies suggest compelling ways to demonstrate to students they have the ability to succeed but may have misjudged the effort required and urging them to invest more effort (Dweck, 2006; Miller \& Geraci, 2011).

Self-efficacy judgments happen before, during, and after learning. They are always expectations of the chances of future success on specific tasks (Bandura, 1997, 2006).However, when students experience unexpected failure and think about what caused the problem they may experience strong negative emotions that influence motivation.

Emotion: For some students, negative emotions such as anger, fear, or depression damage motivation (Bower, 1995; Pekrun, 1993, 2006).Students who value academic tasks, and feel capable of succeeding at them, may become depressed, fearful, or angry enough to search for ways to avoid a task. Strong negative emotions can result from beliefs about what caused problems on an academic task or from negatively perceived experiences in students' lives either inside or outside of an educational setting. Depression sometimes involves thoughts about personal inadequacies that cannot be controlled (Kizibash, Vanderploeg, \& Curtiss, 2002). Fear and anxiety can be connected to uncontrollable events in one's personal life - family illnesses, resource limitations affecting employment or learning, and so on. Anger 
often results from blaming other people or external events for problems (Bower, 1995).Emotions can also be a function of a student's unique background and personality traits and so some students will experience strong negative emotions in situations where others are neutral or positive (Pekrun, Goetz, Titz, \& Perry, 2002).Whatever the cause, there are strategies for helping students to moderate their negative feelings enough to continue working. This is clearly not easy - providing the skilled resources (social or psychological services) to tackle these issues may be the hardest challenge in resolving some motivation problems, yet it is important to recognize the practical impact on learner success if these are not identified and handled.

Strong negative emotions are sometimes the consequence of inaccurate thinking about the cause of failures. These "attribution errors" may also influence motivation.

Attribution errors: Students can value a task, have adequate self-efficacy, and a positive emotional state yet experience an unexpected problem as they pursue a goal. The problem might be a test score far below their expectations or other unexpected negative feedback about their work. Some students recover quickly because they realize they simply did not work consistently enough or hard enough and find ways to overcome their problem such as redoubling their efforts. However, other students experience motivational problems if they believe the cause of negative feedback or failure as due to something outside of their control (Dweck, 2006; Graham, 1991; Weiner \& Kukla, 1970). Erroneous beliefs about uncontrollable causes of academic problems tend to take two different forms: Some students attribute the cause of their failure externally by blaming other people such as teachers they believe to be biased, friends, or others who have distracted them and/or challenging conditions at home (Weiner, 2004).Other students who may have had adequate self-efficacy in the past sometimes respond to an unexpected failure by blaming something uncontrollable about themselves such as for example "I thought I could handle this kind of task but realize now l'm not smart enough" (Dweck, 2006) when more effort would have produced success. This belief error can cause future self-efficacy expectations about the control a student can exercise when faced with a similar learning task where errors were made (Bandura, 1997).

In general, students who believe they have no control over external or internal forces preventing their success will most often quit trying (Weiner, 2004). The solution here is to implement research-tested interventions to help students reframe the cause of the negative feedback to factors controllable by them with greater effort - and then help them design and execute a plan to overcome those factors (Fosterling, 1985; Hall, Hladkyj, Perry, \& Ruthig, 2004).

\section{Challenges for Teachers and Instructional Designers Handling Motivation Problems}

Simply expending more teaching effort in an undifferentiated way on value, efficacy, emotion regulation, and attribution errors for all students may seem appealing, but it can backfire. There is good evidence that when we attempt to give motivational support to students who are already motivated to succeed it is possible to change their values and efficacy in harmful ways. For example, attempts to provide value in the form of rewards for achievement by students who are already motivated can have negative effects (Lepper, Henderlong, \& Gingras, 1999; Reiss, 2005). Under some conditions when motivated students are rewarded for achievement, they tend to change their academic values from interest in a learning task to achieving more rewards. Some students tend to interpret unnecessary support as an indicator their teacher does not think they are capable of doing a task on their own and so their efficacy may actually suffer (Kluger \& DiNisi, 1998; Shute, 2008).Providing extrinsic motivational support to students who do not need it tends to get in the way of building independent learners (Lepper et al., 1999).

Individualized assessment and support for motivation does require considerable effort and resources, yet teacher- or instructional-designer effort is essential to identify and overcome motivation issues. The more diverse the group of students a teacher faces the more diverse the motivation problems they will observe and the more effort is required from teachers, developers, and possibly outside resources (e.g., social services) to identify and help students who are experiencing difficulties. Individual student values, efficacy, attributions, and emotions are determined by culture, identity and family experiences.

The remainder of this article elaborates on what the best evidence and practice experience 
suggests about what data to collect from students who may have motivation problems, and how to use data about these four drivers to diagnose and help students recover from procrastination and inadequate effort. This work is intended to be applied in a range of settings: secondary school, higher education, and workplace training settings.

\section{How to Assess Problems with Motivation}

The two kinds of behaviors that both define motivation and are necessary for all achievement are:

1. Actively starting to pursue a goal rather than merely intending to begin, and once started, persisting over time in the face of distractions; and

2. Investing adequate mental effort to achieve the goal.

After discussing ways to identify problems with each of these two kinds of behaviors, we will look at ways to measure and identify the causes and treatments of the underlying problems leading to increases in motivation. While this discussion emphasizes ways to identify and solve each of the four factors contributing to motivation problems in turn, it is prudent to measure all four together before planning any intervention so multiple motivation issues can be handled together. It is also important to ensure student delays are not due to health, family or work issues that are outside of a student's control.

\section{Starting and Persisting - or Procrastinating?}

When students irrationally and voluntarily delay starting a task long enough "... despite expecting to be worse off for the delay" (P. Steel, 2007, p. 66) and/or once started, allow themselves to be distracted by lower priority tasks or entertainment, they are usually said to be "procrastinating" (Wesley, 1994).Since the factors causing a failure to start or persist appear to be similar, the discussion treats them together.

Arguably, the biggest motivational challenge most students face is starting, then persisting in the face of seductive distractions. P. Steel (2007) estimated $95 \%$ of us have procrastinated at some point but about $75 \%$ of all college students describe themselves as procrastinating often and $50 \%$ admit about a third of their daily activities such as naps, watching TV, playing video games, or talking on the phone are used to avoid working on pressing academic tasks. P. Steel also claimed $90 \%$ of students at all levels indicate they'd like to be able to control their procrastination. Better control seems necessary because those who procrastinate achieve significantly less on avoided tasks than those who begin tasks promptly and persist over time to complete them (Wesley, 1994). Those who procrastinate longer achieve even less than those who procrastinate less (P. Steel, Brothen, \& Wombach, 2001). Helping students start and persist at tasks so they have ample time to do an acceptable job requires a system for the early identification and elimination of procrastination.

\section{Identifying Procrastination -Ask for Tangible Indicators of Progress.}

The simplest and most reliable way to identify a student who is delaying the start of an important task is to require each student to provide tangible evidence of progress on the task at various points before a finished product is scheduled. The activities necessary to complete challenging tasks can usually be divided into phases. The tasks for developers and/or instructors is to require students to submit about three, clearly described and tangible indicators of their progress and provide a reasonable time allotment to complete each of the three phases. Breaking a challenging task into three segments or phases makes it seem more manageable and so may discourage delays based on self-efficacy challenges and/or fear of failure. Instructors should set reasonable progress deadlines and clearly describe how and when progress must be demonstrated - and if necessary, provide tangible examples. For example, if students are writing a paper or tackling a project, ask for a series of reports or drafts starting with a list of the background reading they've chosen, or a paragraph summarizing what they've learned from early reading, or a description of the approach they are taking and/or an outline of the entire paper. Eventually require the submission of a "draft" of parts or all of the paper.

When students are studying for an exam, announce the date of a "practice quiz" covering a clearly identified section of the material covered in the exam. Practice exams can be very brief and questions should be written in the same format as the actual exam.

Requiring progress indicators isn't merely helpful for evaluating procrastination. Breaking a challenging task down into sections or phases has the additional benefit of making the task 
more manageable for students by lowering their cognitive load - a phrase referring to the information contained in the limited amount of thinking space all students have available at any one time to learn (Pass, Touvinen, Tabbers, \& Van Gerven, 2003).It also provides additional opportunities for feedback on the task as it develops. With practice tests, students gain familiarity with the testing format, and they wind up learning significantly more through repeated retrieval, and therefore perform much better on achievement tests (Dunlosky \& Rawson, 2015). One caveat here is the need for instructors to give feedback on these pretasks focused on the strategies students used or should use rather than on the student's general ability or personality (Kluger \& DiNisi, 1998).Pre-tasks require significantly more effort from teachers but the benefits are considerable for students.

In most situations, asking students to submit a number of tangible indicators of progress at a demanding task for review will often defeat procrastination (P. Steel, 2007). With a rich array of student artifacts in hand, teachers and developers can then see which students are struggling with elements of a learning task and with procrastination, and begin checking to see if the issue is a cognitive issue; for example, students may not have mastered some critical decisions or tasks which makes them unable to make the deadline even with substantial effort. Or students may be experiencing a motivation issue, or both. If the problem is cognitive, students often need to acquire missing skills before proceeding. If the problem is motivational, the next stage is to determine whether a persistence problem is due to values, self-efficacy, emotions, or attributional errors - or some combination of two or more of the four factors.

\section{Identifying Mental Effort: Ask how Much Effort They Have Invested}

All learning requires mental effort because new knowledge must be acquired and remembered. Yet the mental effort required to succeed at any learning task is very different for different students because it depends in large measure on the amount of necessary prior knowledge a student brings to the task. For example, when students learn algebra, they are presumed to have mastered necessary prerequisite skills in multiplication and division. A student whose grasp of division is less secure will require more mental effort to begin learning algebra than students with a firmer grasp on the necessary mathematics foundation skills. While it is difficult to measure necessary prior knowledge, there is considerable evidence that it is relatively easier to measure the mental effort a student invests in a learning goal with the brief question described in Figure 1 (Gimino, 2002; Van Gog, Kirschner, Kester, \& Paas, 2012).

Figure 1. Mental Effort Question based on Paas, Touvinen, van Merrienboër, 2006; Gimino, 2002; and Van Gog et al., 2012

$$
\begin{aligned}
& \text { Please candidly describe how much mental effort you invested in } \\
& \text { order to (insert a brief description of the goal of the learning task)? }
\end{aligned}
$$

$\begin{array}{lllll}1 & 2 & 3 & 4 & 5 \\ \text { No } & & \text { Moderate } & & \text { Extreme } \\ \text { Effort } & & \text { Effort } & & \text { Effort }\end{array}$

Note: This one question has been found to be an adequate indicator of the mental effort students believe they have invested in a specific academic task.

Many studies have found questions about mental effort should be asked after each item or problem (or after a short cluster of problems) in a larger instructional program and the mean of the answers should be taken as the best indicator of mental effort (Van Gog et al., 2012). The ideal outcome of this measure is average to higher effort by students who are achieving at desired levels. Students who are in need of help are those whose achievement scores are below expectations but their effort scores average either on the lowest or highest ends of the scale. Students who give very little mental effort and fail to learn may be overconfident (incorrectly believe they already know what they are asked to learn) or they have already learned what is being taught and should not be assigned the task. Students who report investing at the highest level of mental effort and yet fail may not have the prior knowledge they need to succeed and/or are highly anxious.

Unusual motivational problems can occur when students are working in groups or teams. In some groups, one or more individuals have been found to engage in what has been called "social loafing" by letting others do the difficult work (King \& Behnke, 2005). This problem can 
be prevented if the contributions and learning of every member of a group are assessed both by peer review and by more objective measures of individual contributions to the group effort (Condly et al., 2003).

\section{Summary of How to Identify Motivation Problems}

Motivation is defined as starting, persisting, and investing adequate mental effort to achieve learning goals in a reasonable time. These indicators of motivation are assumed to be the product of beliefs and expectations about the amount of control a student can exercise in a specific learning task and context. Starting and persisting can be measured by requiring students to submit tangible evidence of progress throughout a learning exercise.Students who have adequate prior knowledge to learn but do not turn in required progress checks or whose progress checks are inadequate are likely to be procrastinating unless prevented by conditions they cannot control. The contribution of inadequate mental effort can be determined by the average of responses to the effort question (Figure 1). When student work is inadequate and when average answers to the mental effort question are at the lower end, students may be overconfident and failing to invest adequate mental effort to meet minimal achievement standards. When effort investments are at the highest level, students may not have adequate prior knowledge to succeed at the task.

When students experience motivation problems by procrastinating or loafing and so are not putting in adequate mental effort, there are four factors that may have caused their problems. These four factors, briefly discussed earlier, all influence student beliefs and expectations about their chances for success (control) if they invest effort to learn. The four factors are:

1. Values

2. Self-Efficacy

3. Emotions

4. Attribution Errors

To review, all of the factors are distinct but they often interact. Students who value what they must learn will be more inclined to persist and invest effort and vice versa. We tend to value tasks giving us the sense we are effective and so are in control of our lives. Student selfefficacy for any specific learning task is determined by our past experiences and future expectations of success and so influences both persistence and mental effort (Bandura, 1997, 2006).We can have high self-efficacy for a task we do not value (Eccles \& Wigfield, 2002).Students who strongly value a task but have low self-efficacy expectations for their performance on it are strongly inclined to procrastinate and/or are inclined to cheat in order to succeed (Wigfield \& Cambria, 2010).Students who experience strong negative emotions such as anger, fear, or depression may stop persisting and avoid effort altogether (Pekrun, 2006).Finally, when students experience unexpected problems such as a failure or lower than expected performance assessment and attribute the cause to things they can't control (such as inadequate ability to perform the task or a teacher who is prejudiced against them), they will be inclined to stop or reduce their persistence and effort (Dweck, 2006).Provided the student can perform a task by working harder or when prejudice or assessment errors are not involved, this situation is due to an attribution error because they could succeed with greater persistence and effort. Any negative change in any of the four factors can negatively influence or neutralize the benefit of the other three.

\section{Identifying and Solving the Four Factors Causing Motivation Problems}

The discussion turns next to specific strategies for determining the influence of each of the four factors on motivation problems and solutions suggested by research.

\section{Assessing and Solving Value Problems}

Pekrun $(1993,2006)$ provided evidence that the motivational process begins when students assess the value of working on or completing an assigned learning task. If students believe a task and/or the completion of a task is valued enough, they will then examine their expectancies for success by assessing their personal beliefs about their self-efficacy to complete the task. If their value for a task is moderate to high and their self-efficacy is perceived as adequate, they will be more inclined to start and persist at a task and work hard enough to succeed. If they do not value the task, they will be less inclined to start or persist so when students are procrastinating (not starting or persisting soon enough to succeed) it is likely their task value will be low. It is important that values have not been found to influence the 
amount of mental effort students apply to a task (Gimino, 2000; Pintrich \& Schunk, 2002), since the effort required to succeed is apparently believed to be due to our prior knowledge of the task (our self-efficacy).So, students who have high value for a task but moderate selfefficacy will put in more effort than those with very high self-efficacy who apparently believe their expertise on task will permit success with less effort.

\section{Three Types of Values}

Eccles and Wigfield $(1995,2002)$ presented evidence suggesting that the beginning and periodically throughout the entire learning process most students recognize and can be positively influenced to start and persist at a task by one or more of three different types of values.

Interest value: People will more easily and quickly choose to do what interests them the most. Many people are generally curious and interested in mastering a new skill or adding to their expertise. This more "intrinsic" or "mastery" interest pattern often characterizes the most effective learners (Martin \& Marsh, 2008). Others are more interested in impressing others with their capability. These less effective learners may not value a task per se but instead are interested in whether other people believe they are capable of performing difficult tasks. This more "performance" oriented value is important in a competitive sense but less effective for learning than intrinsic mastery interest value (perceptions can be manipulated) but can also be useful under some conditions (Martin \& Marsh, 2008). It is helpful to suggest connections between a current learning task and a student's past or current interests whenever possible.

Importance value: Most people seem more willing to accomplish tasks they believe are important. Importance or "attainment" value is an individual's subjective assessment of whether a task reflects their skill set or identity (Horowitz, 2012). This aspect of value incorporates identity issues because people often think of some types of tasks as central to their view of themselves. So, for example, people who think of themselves as analytical tend to value challenging problem-solving tasks and brainteaser puzzles. Engaging in a task considered to be part of their definition of self presumably allows them to express or validate their identity. To connect with importance value, it is helpful to point out past successes at similar tasks or personal goals expressed by a student reflecting the skills or topic related to their learning goals.

Utility value: So much of what we do is chosen not because we enjoy it or can excel at it but because we want the benefits to future plans when we finish it and/or avoid the negative consequences of failing to finish. This is "utility value" and it shifts a person's value focus from "means" to "ends" although students can have utility value for an intrinsically interesting goal. Students who face an uninteresting task (for example a challenging and uninteresting course) necessary to achieve a future desired outcome (such as a degree or certification) can be asked to focus on the benefits of finishing the task and not on their lack of interest or discomfort about the effort necessary to complete the task at hand. Students who are interested in a goal can also be reminded of its utility value. Utility value is one of the ways we justify enduring something we do not like to get something we do like or avoid something worse. Describing the realistic benefits both of completing a less-desired task or goal and the risks of avoiding it can enhance utility value. It is important not to inflate either the benefits or the risks since overstating value benefits or negative consequences can backfire by damaging people's trust in the value information we provide (Eccles \& Wigfield, 1995).

Measuring students' values for a lesson or elements within a lesson is the best way to determine whether value beliefs might be contributing to student procrastination. A very simple measure based on Eccles and Wigfield $(1995,2002)$ and Condly (1999) for assessing these three kinds of values is presented in Figure 2.Questions one and two inquire about intrinsic interest value. Questions three to five ask about importance value and the remaining two questions focus on extrinsic utility value. 
Figure 2. Questionnaire for Assessing Value for Lessons or Tasks

\begin{tabular}{|c|c|c|c|c|}
\hline \multicolumn{5}{|c|}{ Values Questionnaire } \\
\hline \multicolumn{5}{|c|}{$\begin{array}{l}\text { Please indicate the value you feel for the (topic of lesson) by candidyswering the seven } \\
\text { questions below. }\end{array}$} \\
\hline \multicolumn{5}{|c|}{ 1. In general, I find learning about the (describe topic of lesson) } \\
\hline 1 & 2 & 3 & 4 & 5 \\
\hline very boring & boring & neutral & interesting & very interesting \\
\hline \multicolumn{5}{|c|}{ 2. How much do you like learning about the (topic)? } \\
\hline 1 & 2 & 3 & 4 & 5 \\
\hline not at all & not much & neutral & some what & very much \\
\hline \multicolumn{5}{|c|}{ 3. Is the effort it will take to do well on (topic) questions worthwhile to you? } \\
\hline 1 & 2 & 3 & 4 & 5 \\
\hline not at all & not much & neutral & somewhat & very much \\
\hline \multicolumn{5}{|c|}{ 4. I feel that, to me, being good at solving problems about (topic) is important } \\
\hline 1 & 2 & 3 & 4 & 5 \\
\hline agree strongly & agree & neutral & disagree & strongly disagree \\
\hline \multicolumn{5}{|c|}{ 5. How important is it to you to get good grades on (topic)? } \\
\hline 1 & 2 & 3 & 4 & 5 \\
\hline not at all & not much & neutral & some what & very much \\
\hline \multicolumn{5}{|c|}{ 6. How useful is learning about (topic) for what you want to do after you graduate } \\
\hline 1 & 2 & 3 & 4 & 5 \\
\hline not at all & not much & neutral & somewhat & very much \\
\hline
\end{tabular}

Note: These questions can be provided before, during and after an instructional segment to determine interest (questions 1 and 2), Importance (questions 3, 4 and 5) and utility (questions 6 and 7) value for a task. The three sections are scored separately and used to determine the most promising motivational feedback for students. These questions have not been tested on large numbers of students for reliability and validity.

Wigfield and Cambria (2010) strongly recommended assessing self-efficacy with values before making any decisions about how to solve values-based motivation problems. They point to a number of important interactions between values and self-efficacy.Apathetic students who self-report no value of any kind for learning goals occasionally do so because of very low self-efficacy beliefs. Students who have high utility value (but lower interest and importance values) combined with lower efficacy scores often procrastinate and are more likely to cheat on academic assignments (Wigfield \& Cambria, 2010).

\section{Summary of Values Problems and Solutions}

When students are faced with a learning task, they begin by judging the amount and kind of personal value they have for the task. If they value the task enough, they will start and persist. If they are anxious or frightened about the consequence of poor performance and so value the task too much (for example a passing grade in a feared math course is necessary for graduation) or too little, they are more likely to procrastinate. Requiring tangible progress reports such as drafts of papers and practice-test results for all learning activities discourages procrastination for most students. When students fail to meet progress report deadlines they are candidates for one or more of three kinds of value interventions. Appeal to their interests by suggesting connections between the learning task and interests they have expressed in the past and/or appeal to their identity by describing the task as important because it reflects their stronger skills and/or suggests they "suffer" through a task they dislike because it has utility for their personal goals. Effective value messages result in more consistent completion of progress reports for learning tasks and help to defeat procrastination. Evidence suggests it is best to check for problems with self-efficacy, attribution errors, and negative emotions as well before deciding on a solution to motivation problems.

The discussion turns next to self-efficacy as a contributor to both procrastination and inadequate mental effort.

\section{Assessing and Solving Self-Efficacy Problems}

While values can influence starting and persisting at a task, it has generally not been found to influence mental effort (Clark et al., 2006b).Bandura $(1977,1999,2006)$ has presented 
considerable evidence self-efficacy influences all motivational outcomes and so is a major influence on both the persistence and mental effort required for achievement. Multon, Brown, and Lent (1991) performed a meta-analysis of self-efficacy studies and found appropriate efficacy produced an average achievement advantage on tests and other instructor-graded projects of $20 \%$ for even the most challenged students. Perceived self-efficacy is defined as people's beliefs about their capability and expectations for success. If we believe we are not able to succeed, we will generally be reluctant to start, persist once started, or invest mental effort to avoid failure. If we feel we have maximum efficacy, we may start a task but are not going to be inclined to invest much effort. Why should we work hard if we feel we already have the skills being taught? Thus, the relationship between self-efficacy and effort is best described as an inverted $U$ (see Figure 3). Moderate self-efficacy about new learning tasks is usually the most desirable level because it leads to the maximum effort required for success (Gimino, 2000; Flad, 2002)

Figure 3. Inverted "U" Relationship between Perceived Self-efficacy and Mental Effort (following Gimino, 2000, Flad 2002)

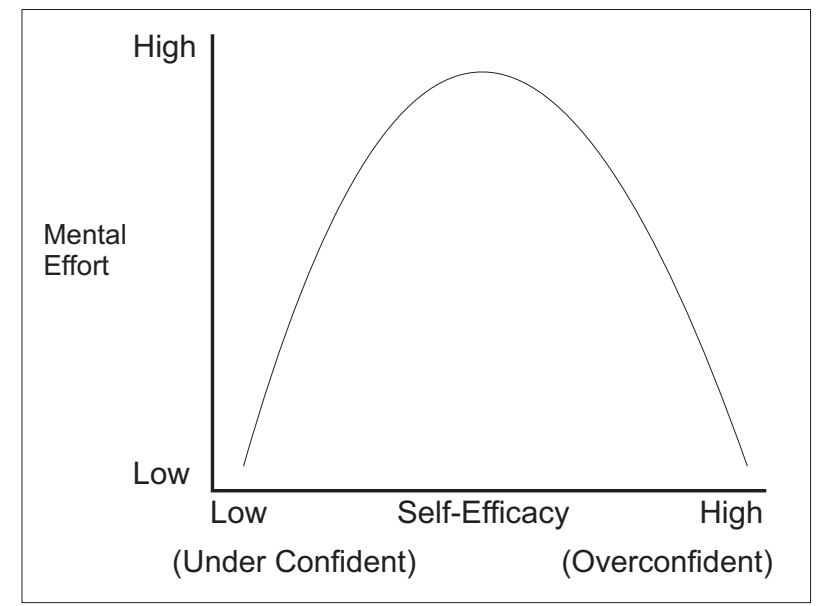

Bandura $(1999,2006)$ has cautioned that student self-efficacy beliefs are most accurate when they are focused on specific academic tasks. So, for example, it is not helpful to ask students about their confidence in their mathematics ability or even about their confidence in a specific area in math such as algebra. More focused questions (for example, whether they can solve single variable equations in algebra) would be better predictors of procrastination and inadequate mental effort. In most instances, first showing students an example of quiz items or a specific paper assignment followed by asking how confident they are they can succeed at these tasks is the recommended approach to an accurate assessment of selfefficacy.Bandura (2006) has provided a recipe for developing individual and group assessments of self-efficacy (see Figure 4). 
Figure 4.Self-efficacy Scale following Bandura (2006)

Self-Efficacy Questionnaire

In a few minutes, you will be asked to answer xx questions on (topics) in xx minutes. These questions will be similar to the one appearing below:

INSERT SAMPLE QUIZQUESTION OR DESCRIPTION OF LEARNING TASK AS AN EXAMPLE OF THE TASK STUDENTS WILL FACE.

Below please rate how confident you are that you can answer the upcoming problems (handle the task described) in the example above. Rate your degree of confidence in $10 \%$ intervals by recording a number from $0 \%$ to $100 \%$ in each of the blanks using the scale below:

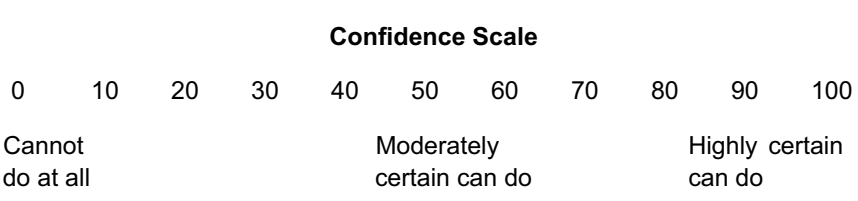

How confident are you that you can:

Correctly answer at least $25 \%$ of the xx questions

Correctly answer at least $50 \%$ of the $x x$ questions

Correctly answer at least $75 \%$ of the $x x$ questions

Correctly answer all $100 \%$ of the $x x$ questions

OR

How confident are you that your grade on this project will at least be: $(0-100 \%)$

A

B

C

Fail

Note: This form must be revised and be tailored to a specific test or project. Students who judge their self-efficacy below 40 or above 70 percent may not be inclined to invest adequate effort to succeed. Students with moderate self-efficacy scores in the range of 40 to 70 percent with repeated measures on Bandura's scale are likely to invest the most effort.

In general, as self-efficacy increases to a moderate level so does achievement. Students tend to be fairly accurate about the chances they will succeed at academic tasks when they are somewhat familiar with the tasks they face. Yet some students tend to over or under estimate their efficacy. Low self-efficacy increases the chances of both procrastination and a refusal to invest effort. Extremely high self-efficacy results in low effort also - primarily because, as mentioned earlier, students believe they already know what they are being asked to learn.

When students judge their efficacy as low they do so for at least two reasons. On the one hand, they may recognize they do not have some of the prerequisite skills required to learn with and so realize success may not be possible without much more effort than they want or are able to invest. These students may need a cognitive intervention - remedial instruction before tackling a learning task they are not prepared to handle. This is more common in subject matter areas where students have had difficulty in the past. If it is determined these students can succeed with extra effort they need to know they will receive extra support to gain the skills they need to succeed to help them believe they can succeed. It is important to tell students they are not responsible for their difficulty because if we had better ways to assess "prior relevant knowledge" they would have been offered remedial help earlier (maybe years earlier) to insure they succeeded. Teachers also need to reassure students "We can help you get the missing strategies if you are willing to work a bit harder."

On the other hand, students may be competent but may misjudge their ability and believe that they can't learn. There is evidence this belief is often supported when teachers express sympathy to students who encounter learning problems (Shute, 2008).Sympathy for failure or difficulty is sometimes interpreted as "I knew you would not succeed because of your lack of ability and am sorry you are unable."The mistaken belief "I can't learn this" may also be due in part to student's familiarity with common but inaccurate stereotypes such as "women can't learn math" or "African Americans don't do well on tests."This phenomenon, called "stereotype threat" (C. M. Steele, 1997; C. M. Steele \& Aronson, 1995) results in significantly lower academic performance for students who have the necessary skills to achieve at a higher 
level. When stereotype threat is presumed to be the cause of motivational problems, changing the way tests and other academic tasks are presented to students can reduce it. Stone, Lynch Sjomeling, and Darley (1999) recommend emphasizing an individual or group's strengths rather than denying a stereotype about a presumed weakness when describing a test or other academic task. Yet when teachers or test instructions simply point out a person's membership in a group victimized by stereotypes about learning difficulties, the attention directed to the false belief can lead to self-efficacy problems (C. M. Steel \& Aronson, 1995) so it may be more supportive not to mention stereotypes.

\section{Group Efficacy Problems and Solutions}

Students are often asked to work together in small cooperative groups to achieve learning goals. In most cases, the product of the group work is evaluated and group members share the same grade. Karua and Williams (1995) argued that when one or more groups in a class fail to achieve expected results a likely cause is "social loafing" defined as decreased performance of about $20 \%$ because one or more group members expect their skills are not important for group success and so are letting others do the work. These loafing students often have lower self-efficacy and have attributed higher efficacy to other group members. The solution here is to convince every member of a cooperative group about the need for their individual contributions to the group effort and the need for individual evaluation of their work by other group members and by an instructor. This condition is more easily implemented if every member of a group is assigned a unique task that is needed to accomplish the interdependent group goal. Under these two conditions, social loafing more or less disappears (Condly et al., 2003; Karua \& Williams, 1995).

It is somewhat ironic that inadequate mental effort is related to both the lowest and highest self-efficacy levels. While most educators are sensitive to the negative consequences of inaccurately low self-efficacy, more destructive motivational problems (especially with older, less experienced learners, e.g., community college or workplace training settings) are caused by inaccurately high self-efficacy. Overconfident students generally believe they already know what they've been asked to learn and so do not invest effort to learn the new knowledge necessary to achieve goals. The consequences of this belief are twofold: first overconfident students tend to use familiar approaches requiring minimal effort but their approach is inadequate and leads to failure and negative feedback. The second consequence is since they believe they know how to succeed, they tend to defensively reject negative performance assessments as due to teacher bias, faulty evaluation (bad tests), or other external causes. Mezulis, Abramson, Hyde, and Hankin (2004) presented compelling evidence that about onethird of the time, students will project the cause of failures externally in a self-serving way. They also point out the most challenged students also tend to be the most overconfident.

\section{Self-efficacy Solutions}

One of the benefits of assessing self-efficacy at the time assignments are made is compelling evidence that when student self-efficacy is significantly higher than grades or instructor assessment indicates students will "kill the feedback" by rejecting and ignoring instructors' advice (see Winstone, Nash, Parker, \& Rountree, 2016, p. 22). This evidence suggests the need to take special care on feedback for overconfident students. Over confident students must be convinced the cause of their poor performance was not their general ability but instead the need for a different approach to the specific task at hand (Kluger \& DiNisi, 1998). One strategy teachers report using effectively is to ask how they performed the task and then tell them you can see why they thought their strategy would work. Then explain the task is misleading and show them how the task is different than they originally believed, propose a more successful approach, and ask them to "try it this way" even though it "takes a bit more effort."

A very important point about the most effective instructor feedback comes from a review of feedback research by Kluger and DiNisi (1998) conducted in many cultures and nations. They concluded that the most effective feedback about failure to children and adults who encounter difficulties must focus on the need to use different strategies to succeed at the task, not on people's ability, intelligence, or intentions. They found no differences in different cultures or national groups. As the section on attribution errors will demonstrate, focusing feedback on ability or intelligence not only does not help, it tends to further damage persistence and mental effort. 
Finally, Ashford, Edmonds, and French (2010) conducted a meta-analysis of many studies where researchers tried to adjust inaccurate self-efficacy judgments. They found asking or reminding students about past situations where their self-efficacy was at a more helpful level on similar tasks and/or describing a specific future scenario where the student would follow suggestions for a more productive self-efficacy level produced the highest levels of selfefficacy change.

\section{Self-efficacy Summary}

Self-efficacy is a measure of people's belief about their capability to succeed at a goal. The most effective measures of self-efficacy are targeted to very specific goals. As self-efficacy increases to a moderate level, students are less likely to procrastinate and are more likely to invest adequate mental effort. Yet as efficacy increases to very high (overconfident) levels the reverse happens - effort decreases and learning suffers. When students value a task, but procrastinate or fail to perform as expected they are likely to have either very low or very high self-efficacy. It is important to determine whether low self-efficacy students have the skills necessary to succeed at the task they are avoiding or failing. If they lack skills, they need assurance they are not responsible for their problem and will be given support to acquire the skills they need and also if they work hard to use these new skills they will succeed.(Of course, effective support has to be provided.) If they have the skill to succeed but believe they do not, they need to be reminded of successes at similar tasks in the past. It may be best if teachers do not mention negative stereotypes before a test or high-stakes project, and should not express sympathy after students have difficulty on a learning task; both, unfortunately, are likely to be counter-productive. The best feedback when students with low self-efficacy have difficulty is "You have the skill needed and can do it with a bit more effort."We need to be alert to the fact that some students in collaborative learning groups or teams "loaf" to let others do their group work. Having group members and the teacher stress the importance of individual efforts and formally evaluate the contributions of each group member can eliminate "social loafing."Finally, inadequate mental effort may also be due to over confidence. Students with excessive self-efficacy wrongly believe they already know what they need to learn and so spend very little effort, then often react with anger when they receive negative feedback. It helps to ask these students what strategies they used, then point out while they are generally very capable, their approach to this specific task might need to be modified a bit and in the past successful students took a different (more effective) approach and ask them to repeat the task using a different strategy. In all instances, feedback to students who do not do well must be focused on the strategies they used, not on their intelligence, attitude, or intentions.

The next factor in the BEC framework influencing persisting at tasks and mental effort on them is our emotions.

\section{Assessing and Solving Emotion Problems}

Students who value learning goals and initially have both adequate self-efficacy and controllable attributions for failure may experience motivation problems if they are in the grips of strong negative emotions. Emotions are always present during thinking, problem solving, and learning (Immordino-Yang \& Damasio, 2007); negative emotions may stem from events not connected to academic failure. Anger, depression, and fear may be the result of a belief we've lost control in situations where the loss is perceived as harmful. This loss is more acute when it is focused on a current event such as a failing grade on a quiz or paper in a critical course or a personal problem outside of a course. Some students recover from bad experiences quickly and in the case of academic problems, resolve to work harder. Others have difficulty and the fallout from a failure to control negative emotions can lead students to quit trying. These differences in emotional recovery span the range of what has been called "emotional intelligence" (Song, Pang, Peng, Law, Wong, \& Chen, 2010).Weiner (1986) provided evidence that when students believe external factors caused their failure experience they often experience anger. When their attributions for failure are internal ("I did not work hard enough" or "I'm not smart enough") they tend to experience depression and guilt or shame feelings. When failures increase, the likelihood of a larger failure (for example when a failed mid-term quiz is a large part of a final grade or when failures threaten job security) students also become anxious or frightened. Negative moods have also been found to focus student thoughts on past failures and may lower self-efficacy so students expect less of future attempts at the same task. Strong negative emotions also have a negative influence on cognitive load (Pass, van Gog, \& Sweller, 2010; Sweller, 1988).Precious "thinking space" in 
the mind is affected by negative thinking and rumination accompanying negative emotions and leaves inadequate space for thinking productively about learning tasks and goals.

Depressed, angry, or fearful students tend to withdraw, procrastinate, and quit working hard and sometimes invent face-saving lies about illness, family or job demands (Bower, 1995; Pekrun et al., 2002).Positive, happy, optimistic students report procrastinating less, working harder, and achieve more (Boekaerts, 1993; Bower, 1995; Um, Plass, Hayward, \& Homer, 2012). Figure 5 describes a self-report instrument used successfully to identify negative emotions that might have contributed to motivation problems.

Figure 5. Emotions Questionnaire based on Pekrun, 2006

\begin{tabular}{|c|c|c|c|c|c|}
\hline \multicolumn{6}{|c|}{$\begin{array}{l}\text { Emotions Questionnaire } \\
\text { Studying topics, like (list topic), can induce different feelings These questions } \\
\text { refer to emotions you may experience in studying about (topic) today Please } \\
\text { candidly indicate how you currently feel about studying this topic }\end{array}$} \\
\hline & $\begin{array}{c}\mathbf{1} \\
\text { Strongly } \\
\text { Disagree }\end{array}$ & $\begin{array}{c}\mathbf{2} \\
\text { Disagree }\end{array}$ & $\begin{array}{c}\mathbf{3} \\
\text { Neutral }\end{array}$ & $\begin{array}{c}4 \\
\text { Agree }\end{array}$ & $\begin{array}{c}\mathbf{5} \\
\text { Strongly } \\
\text { Agree }\end{array}$ \\
\hline $\begin{array}{l}\text { 1. I feel very happy } \\
\text { and want to study. }\end{array}$ & & & & & \\
\hline $\begin{array}{l}\text { 2. I'm irritated and } \\
\text { somewhat angry and } \\
\text { don't feel like } \\
\text { studying. }\end{array}$ & & & & & \\
\hline $\begin{array}{l}\text { 3. I feel so frightened } \\
\text { about failing that I } \\
\text { can't give my } \\
\text { studies my full } \\
\text { efforts. }\end{array}$ & & & & & \\
\hline $\begin{array}{l}\text { 4. I feel positive and } \\
\text { optimistic and am } \\
\text { looking forward to } \\
\text { learning. }\end{array}$ & & & & & \\
\hline $\begin{array}{l}\text { 5. I feel depressed and } \\
\text { pessimistic and those } \\
\text { feelings undermine } \\
\text { all my energy. }\end{array}$ & & & & & \\
\hline
\end{tabular}

NOTE: Items 1 and 4 are reverse scored. Students who indicate strong negative emotions after failing are less likely to persist and invest more effort and so are in need of intervention. Students who are angry (item 2) are likely to project blame for their failure and when depressed (item 5) are inclined to take responsibility (perhaps too much), and the most at risk students combine strong agreement on items 2 and 3.

\section{Solving Emotion Problems}

The goal is to help students who are experiencing strong negative emotions that are interfering with their focus on academic tasks to become more positive and willing to persist and work hard to recover from their perceived loss. Interventions administered by teachers or friends that have been found to change negative mood states include powerful active listening activity teachers can use to help students get control of their emotions and be open to alternative views of what happened (Ames, Maissen, \& Brockner, 2012; Weger, Bell, Minei, \& Robinson, 2014).Active listening is a three-stage process:

1. Ask the student what they believe caused their learning problem and listen carefully and non judgmentally to their answer;

2. When they finish, succinctly summarize the cause(s) they described back to them - again in a neutral, nonjudgmental way (do not agree or disagree) - and ask, "Did I understand you correctly?"If they say yes, they will often feel less negative emotion and be more willing to discuss solutions.

3. If they say "no," ask them what you misunderstood and repeat step 2 only twice. If they don't think you understand after two attempts, then ask them to think about it and arrange a meeting to repeat the active listening the next day

Other strategies for helping students with strong emotions: suggest giving them the opportunity to listen to the music they like best; asking them to describe a personal, positive mood-related experience in a paragraph, or giving a short talk and/or watching a video or 
listening to stories emphasizing positive mood states (Bower, 1995).Corno and Kanfer (1993) demonstrated positive mood changes using emotion control training that included allowing students to choose the setting where they study or where testing will occur and teaching students to use "positive self-talk" such as "Think of ways to make this kind of task (exam) more fun or less scary to me in the future," "Sing to myself when I feel frightened," "Listen to my breathing and let my body relax then count slowly to 10 so I don't feel so angry," "Force myself to do anything active when I feel depressed," "Plan to ask for help from friends or teachers," "Think of times in the past when l've recovered from this kind of disappointment - I can do it again."

It is also important to note that between 5 and $20 \%$ of distressed students will not respond to any attempt at emotional self-regulation - most often because they need the support of a psychologist or other social or medical services. In poverty settings, the percent of students needing support a teacher cannot provide is likely much higher.

\section{Emotion Summary}

Strong negative emotions interfering with persistence and mental effort may occur when students fail unexpectedly even when they value a task and have adequate selfefficacy.Disruptive emotions can also spill over from non-academic situations such as trouble at home, work, or with peers and interfere with schoolwork. Whatever the source, we can sometimes help students control their emotions enough to continue working if you use the active listening approach or by using mood changing strategies such as those suggested by Bower (1995) - listening to liked music, describing or reading positive emotional experiences and/or the "positive self-talk" approach suggested by Corno and Kanfer (1993).Trusted, positive, and empathetic teachers are most helpful to students with negative emotions. If instructor support seems inappropriate or fails, then consider offering to assist them in finding social services or medical support.

The discussion turns next to the motivational challenge students experience when they encounter a failure experience and believe it is caused by something they can't control.

\section{Assessing and Solving Attributional Error Problems}

Whenever something happens that is viewed as important but negative and unexpected, we are all driven to explain why the negative event occurred (Weiner, 1986, 2004) by attributing it to some cause. When students attribute the cause of a failure in the form of a poor grade on a quiz, paper, or other assignment to something they can't control, they most often quit trying. Weiner (1986) categorized the four kinds of attributions students provide to themselves for failing to perform as expected (see Figure 6). He divided failure attributions into two types: External causes (something outside or external to ourselves such as teacher prejudice "My teacher hates me" or "My job is too demanding and I don't have enough time to study" or "I'm a person who has consistently bad luck on tests") and Internal causes (stemming from ourselves such as "I was busy before this test and did not spend enough time studying").He then divided the internal and external "locations" of causes into those considered to be controllable or solvable and stable or uncontrollable causes. An example of a controllable internal cause would be a lack of effort and an external controllable cause might be an unusually demanding time at work or a storm led to a computer failure when electrical power was temporarily interrupted. An uncontrollable internal cause might be the student's belief they lack the intelligence to succeed; another would be a failure perceived to be due to a biased teacher. Some causes that could not be controlled when they happened (temporary job demands, a family crisis, temporary illness) should not be expected to persist and cause future problems. He also suggested one way to determine the cause students assign to their problem can be determined indirectly from the emotion they display. Regret and guilt are often healthy indicators that occur when students realize they did not work hard enough but shame or anger may indicate beliefs in uncontrollable causes. Weiner (1986) offered considerable evidence the locations of attributions (internal or external) were less important than whether student attributions were stable (uncontrollable) or unstable (controllable). When students believe their poor performance was due to a cause they can directly or indirectly influence, they tend to recover more quickly and continue to work. 
Figure 6. Location and Stability Attributions Students Use to Explain Poor Performance on Academic Tasks - following (Weiner, 1986)

\begin{tabular}{|llll|}
\hline & & \multicolumn{2}{c|}{ Stability of Attributions } \\
& Controllable & Uncontrollable \\
& Internal & $\begin{array}{l}\text { Inadequate } \\
\text { Effort }\end{array}$ & $\begin{array}{l}\text { Inadequate } \\
\text { Intelligence } \\
\text { (Shame/Sadness) }\end{array}$ \\
$\begin{array}{l}\text { Location of Student } \\
\text { Attributions } \\
\text { for Failure }\end{array}$ & & (Guilt/Regret) & (Shacher Bias \\
& External & $\begin{array}{l}\text { Bad Luck } \\
\text { (Hope) }\end{array}$ & $\begin{array}{l}\text { Teacher } \\
\text { (Anger) }\end{array}$ \\
\hline
\end{tabular}

Note: Emotions associated with attributions are in parentheses. Students stop persisting and investing effort when they attribute poor performance to uncontrollable causes

\section{Belief in Uncontrollable Causes for Failure}

The belief that learning problems are uncontrollable is typically attributed to a lack of intelligence in western societies. Some students who encounter negative feedback believe they can't succeed because they are not smart enough and since they also tend to believe intelligence cannot be controlled, they most often quit trying. This includes students who have been taught or have experienced people expressing the belief "woman can't do math."Dweck (2006; Yeager \& Dweck, 2012) described this belief as a negative "mindset" and offered evidence it is due in large measure to the western emphasis on the importance of intelligence and our inclination to praise children for being "smart" and attributing learning and performance achievement to their intelligence rather than to their effort. This mindset also causes students to lower their self-efficacy when they encounter learning problems. Teachers should consider attempting to help students focus on effort rather than intelligence as the cause of their successes as well as the solution to many of their problems.

Assessing attributions. A number of attributional measures have been developed. Most of the measures are focused on specific events and are based on early work by Peterson, Semmel, von Baeyer, Abramson, Metalsky and Seligman (1982). The measure depicted in Figure 7 mirrors some of these efforts but its reliability and validity have not been determined. It is offered as a way for teachers and advisors to start a dialogue with students about the cause of their failure experience if students believe the cause of their problem is more or less uncontrollable.

Figure 7. Attribution Questionnaire

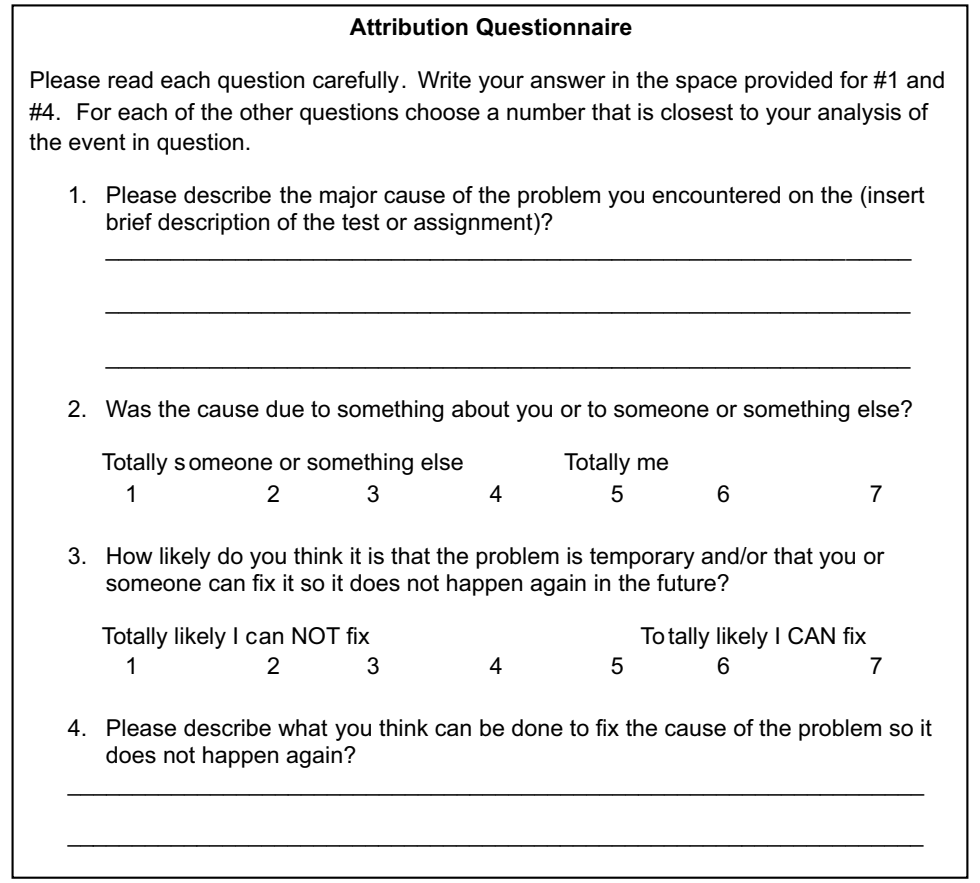


Note: This questionnaire has not been tested for reliability and validity with large numbers of students and is offered only to start a conversation between teachers or advisors with students who have experienced failure.

Solving attributional error problems: If students believe they cannot "fix" the problem causing their failure, a helpful one-on-one dialogue about the problem may be beneficial. Evidence suggests the most effective strategy for regulating persistence and effort problems caused by perceptions of either internal or external uncontrollable negative experiences may be a combination of active listening and "cognitive reappraisal" or "rethinking causes" (Troy, Shallcross, \& Mauss, 2016).Instructors should consider describing rethinking strategies at the start of a course so they can remind students of the strategy when they want to quit working in response to negative feedback.

Breathe, label, listen, rethink strategy: An effective version of the listening and rethinking strategy involves four stages:

1. Breathe: Ask students to take three slow, deep breaths to get more oxygen to the brain and calm down a bit so the emotion can be handled;

2. Label: Ask the student to describe their emotion; for example, "I'm angry" or "I feel depressed" or "I feel scared" to decrease the strength of the emotion;

3. Listen Actively: Teachers should use the active listening strategy described above in the section on emotions, then when the student agrees you understand what they feel caused the problem,

4. Rethink (or reattribute): After actively listening, suggest a less upsetting reason or cause for the event that led to the strong negative emotion. For example, "Maybe you simply experienced a brain cramp or a bad day and the failure does not mean there is anything wrong with you;" or "Bad stuff happens and life has to go on;" and/or "The only thing to fear in this situation is fear itself because that will cause a self-fulfilling prophecy."

It is very important to avoid using the cognitive reappraisal for motivation problems when the student believes the cause is controllable since there is evidence it can backfire. Apparently if people who encounter controllable problems reduce the personal negative impact they experience, they are not as inclined to solve the problem (Troy et al., 2016).Instructors should consider teaching students who encounter uncontrollable causes of failures the Breathe, Label, Listen (to yourself) and Rethink strategy for dealing with failure or negative feedback but only if the student believes their situation is hopeless.

Look for controllable causes and make plans: If you have difficulty when you ask students to rethink the cause of their problems, consider another strategy:

1. Begin by explaining you understand their reason for the problem but wish they would reconsider and discuss it with you.

2. Problem-solve with the student by asking how much time they spent working towards the goal and if there might be any other possible cause for the problem they encountered.

\section{Make a specific plan and help them monitor their progress.}

As you discuss the problem (stage 2) with students who insist on uncontrollable external attributions, it is important to either suggest ways they can indirectly influence the cause and ask them to think about a way they could spend more time and effort on this kind of task in the future. The solution Dweck (2006) offered to support student's use of internal, controllable attributions for mistakes and failures is advice to parents and teachers to begin very early in life to attribute success and failure to student effort rather than to aptitude or intelligence and remind students that even the most intelligent people must consistently work hard to achieve their goals. She also suggested we inform students that as they learn, their knowledge-based intelligence increases, so working hard "makes you smarter."Yet the diversity of students in most educational settings insures some who procrastinate or fail to work hard enough will attribute negative feedback externally to something uncontrollable other than lack of ability such as an unfair teacher or tests that are consistently impossible to pass. Bias is often perceived as stable and uncontrollable so students who think a teacher is prejudiced against them often quit trying. Hopefully this attribution is inaccurate though minority students often have experiences making their bias attribution understandable and too often accurate. Provided bias is not present (and some students may need to be persuaded it is not a factor) then the solution here is to ask the student to consider they only had temporary "bad luck" or 
encountered a challenging test format or and those future tasks might not be as difficult. Note the solution focuses the cause of the difficulty externally - the same "location" as the student's first attribution - but it often helps to advise students to try putting in more effort next time. Forsterling (1985) described compelling evidence supporting attempts to convince students to reattribute failure away from uncontrollable causes to lack of effort and produce increased persistence and improved academic performance.

In the past, researchers have also successfully tested "attributional retraining" programs to help students avoid attributional errors. Participants are generally given specific information about attribution processes, shown videotaped simulations of negative and positive attributions using actors, and then engaged in discussion about the benefits of various kinds of attributions in a variety of situations (Hall et al., 2004).In other programs, causal attributions are one phase within a larger cycle of self-aware analysis of learning strategies and outcomes (Cleary \& Zimmerman, 2004).Attribution retraining has been shown to have significant positive effects across multiple areas of performance and achievement. This kind of solution may be best provided by institutional social or psychological services.

\section{Attribution Errors Summary}

When students value a task and have moderate self-efficacy but encounter negative feedback they must search for an explanation. While some students attribute the cause to internal factors (lack of effort or aptitude) others tend to project the cause externally (bad luck, biased teachers). Yet the location of the cause is less important for motivation than is the perceived controllability of the cause. Most people believe their luck changes, and effort can be controlled so these attributions do not cause motivation problems. However, when learning difficulties are attributed to uncontrollable causes such as intelligence and teacher bias, able students tend to quit trying. Use the questionnaire provided to ask students what they think caused their problem and if possible; also note the emotion they are experiencing. Anger suggests external uncontrollable attributions such as prejudice and shame often follow internal attributions to aptitude. Solutions to attributional errors should reflect the location (internal or external) and urge the student to consider other controllable causes such as study time and effort. Start by using the Breath, Label, Listen, and Rethink strategy described earlier.

If students are still focused on an uncontrollable cause for their problem, use a three-stage challenge approach where you

1. Challenge: Let students know you disagree and ask them to discuss the issues with you;

2. Problem-solve with them to find controllable solutions that, if possible, reflect the internal or external nature of their attributional error; and

3. Plan and Monitor: Work with them to make a plan and monitor the results.

\section{Conclusion}

While motivation is as important to learning as the instructional methods used by teachers and the learning strategies we teach students, it does not receive the attention it deserves from researchers or funding agencies. This article is intended to start a dialogue about the need for more practical, evidence-based studies of motivation strategies based firmly on solid research and clinical experience in order to accurately identify and solve motivational problems. This article has attempted to tip the scales a bit by describing the BeliefExpectancy-Control (BEC) motivation Framework - an evidence-based learning engineering approach to collecting data in diverse learning contexts, as well as handling motivation problems experienced by adolescent and adult students.

In order to identify motivation problems and separate them from learning strategy problems, teachers or instructional designers must try to defeat procrastination by asking students to tackle instructional goals in stages and provide concrete evidence they have completed each stage on time. This requirement allows teachers or computer monitoring to identify students who are not starting or persisting at learning tasks. For students who complete stages of their assigned work on time but whose work fails to achieve minimum standards, it also provides a way to assess whether the failure was due to a lack of needed prerequisite knowledge or due in part to a lack of adequate effort. The BEC framework also recommends that parents and teachers strive to help students avoid a rigid, intelligence-based mindset about the role of IQ in 
their learning by emphasizing the need for hard work, regardless of intelligence level, to succeed at all things in life. This belief in hard work, once established, helps more mature students accept the responsibility for procrastination and not working hard enough to succeed. Finally, the BEC framework offers four factors - values, self-efficacy, emotions, and attribution errors - as both the primary causes of and as solutions for motivation problems. Assessment instruments and strategies for analyzing student difficulties using one or more of the four factors are the core of the Framework. Specific steps for assessing, evaluating, and solving motivation problems based on this discussion are presented in an appendix at the end of this article.

The BEC Framework is not offered as a theory or as a set of research hypotheses. Instead it provides a learning engineering (Saxberg, 2015) structure for applying existing motivation research and the clinical experience of teachers to identify and solve motivation-based learning problems for students who procrastinate and/or fail to work hard enough. It is offered as an open system that will change as we benefit from the results of its application through clinical experience "on the ground" about motivation problems and solutions. It can be implemented in the classroom or online in distance education.

\section{Appendix}

Suggestions for using the information in this article to help students with learning problems

\section{How to Design Motivation Support for Students While Planning a Course:}

These suggestions are offered to help apply the Belief-Expectations-Control Framework and are offered as general guidelines based on the experiences reported to the authors by teachers and instructional designers.

IF you want to maximize motivation to learn and you wish to discourage procrastination, THEN begin with the list of bullet points below and when you have completed the planning activities described in the bullet points below and confront student motivation problems, move to the next sections to identify some of the common causes of motivation problems by administering, scoring, and interpreting answers to the questions described in the discussion;

Design and schedule at least 2 to 3 progress checks in the form of practice quizzes or progress reports in advance of the due date for every major quiz or project in order to discourage procrastination;

Format a separate test item for the single "mental effort" question in Figure 1 tailored to each progress check, every quiz, and/or project;

Format a questionnaire containing items from Figures 2, 4, 5 and 7 for students who experience motivation problems and give the questionnaires only to students who experience learning problems ("If motivation is not broken, don't fix it");

When you give any feedback on class performance to a student, make certain that you focus it on the specific strategies or behaviors (or lack thereof) that may have caused a problem or helped them succeed and not attribute success or failure to their intelligence, attitude, or personality;

Always attribute success to hard work and persistence and failure to a lack of effort or being distracted from studying unless students have encountered a problem they cannot control;

Do not express sympathy for learning problems that could have been avoided or solved by a student - it is too often interpreted by students as due to your belief they are not able to succeed. Instead express your firm belief they can succeed IF they invest a bit more effort, avoid becoming distracted;

IF your course will require team or collaborative group work on projects, THEN plan for and announce that you and/or group members will evaluate the individual contributions of each team or group member on all group work to ensure everyone contributes to the best of their ability. Plan to explain this approach in order to discourage "social loafing;"

Keep in mind the fact that as a teacher your own motivation can be a problem. Giving your students learning AND motivation support will insure more of them succeed in your course but it also requires considerable effort from you. Use the BEC framework to assess and solve your own motivational challenges.

Scoring and Interpreting the Mental Effort Question (Figure 1): 
IF possible, give the mental effort question to all students after every progress check, test, or project is completed. When you've given it a number of times on the same or similar activities, compute a mean (Sum X/n) to find an average mental effort score for each student.

\section{Overconfidence?}

IF a student is having learning difficulties and their individual or averaged mental effort scores are very low, THEN assume they MAY be overconfident, meet with them, listen actively and non judgmentally to their reaction to the difficulty and suggest they may not be using effective strategies to succeed, describe effective strategies, suggest they will succeed if they use the new strategies and work harder - and ask them to redo the assignment and promise help if they need it and to check to see if they are succeeding.

\section{Prerequisite Knowledge OR Uncontrollable Personal Problems?}

IF a student has very high mental effort scores but performs below expectations on a progress check, quiz, or project, THEN meet individually and try to decide whether they have the prerequisite knowledge and skills they needed in advance of your course in order to succeed OR if their problem is caused by a personal issue they cannot control such as a serious family, job, or health problem;

IF students need prerequisite skills or have an uncontrollable personal problem, THEN express empathy and find a way to provide needed skills;

OR give them empathy for their personal problem and suggest services available to help them if possible.

\section{Scoring and Interpreting the Remainder of the Motivation Questionnaire:}

IF a learning problem is NOT caused by a lack of prerequisite skills OR an uncontrollable personal issue, THEN ask the student to candidly fill in the motivation questionnaire and promise to meet with them again and help them once you review their answers.

\section{Scoring Self-efficacy (Figure 4) and Values (Figure 2):}

First score the self-efficacy question (Figure 4) and place the student's self-efficacy on the specific quiz or project in either Low (0 to $30 \%$ ), Moderate (31 to $69 \%$ ) or High (70\% to $100 \%$ ).

Next score the three sections of the Values questions (Figure 2) and classify the student's values as:

- Hi Interest (average 3.5 or higher on Questions 1 and 2)

- Hi Importance (average 3.5 or higher on Questions 3, 4, and 5)

- Hi Utility (average 3.5 or higher on Questions 6 and 7)

\section{Interpreting the Self-efficacy (Figure 4) and Value (Figure 2) Items:}

IF students score Lower on Self-efficacy AND Higher on Interest and/or Importance and/or Utility, THEN they may be at risk because they lack self-efficacy on a task they feel is important to them so are much more likely to avoid effort and allow themselves to be distracted from working and so procrastinate despite your best effort to discourage procrastination with progress checks and also more likely to cheat on tests or projects.

Approach: This student needs to be reassured they have the skills to handle the tests or projects - remind them of past successes in your class or previous classes and strongly suggest they need to invest more effort; discuss strategies that will help and offer to review their work if they are willing to work a bit harder.

IF students score moderate on self-efficacy but are low on one or two of the value items, THEN they may not have worked very hard or persistently and so need value feedback focused on the type of value(s) they rank higher.

\section{Approach: IF the personal value they have for the assignment is:}

Higher on Interest (average 3.5 or higher on Questions 1 and 2 in Figure 2), THEN tell the student this kind of value characterizes the most effective students and they only need to work harder and persist longer to succeed. Ask them to check back with you later to see if what you recommend is working.

Higher on Importance (average 3.5 or higher on Questions 3, 4, and 5 in Figure 2), THEN tell the student they are good at this kind of task and so it is likely they were distracted and only need to work more consistently and harder to succeed. IF this student scores high on self- 
efficacy, they may need overconfident feedback. Ask them to check back with you later to see if what you recommend is working.

Higher on Utility (average 3.5 or higher on Questions 6 and 7 in Figure 2), THEN reassure the student that so many learning goals are less interesting but are necessary for them to achieve a larger goal. Explain that if they only tolerate not liking the task, focus their mind on the goal they will achieve if they work harder at it, and invest more effort they will succeed. Ask them to check back with you later to see if what you recommend is working.

IF students score High on Self-efficacy (Figure 4) and Low on Effort (Figure 1),THEN they are even more likely to be overconfident and not inclined to either work hard on this exercise or accept personal responsibility for the learning problem they've encountered.

Approach: This student must be persuaded that while they are a very capable student, the approach they used on the test or project may have been successful in the past but did not help them on this assignment - suggest they need a new approach and much more effort invested in order to succeed now. Describe study plans or project-completion skills successful students have used and ask this student if they are willing to apply them. Ask the student to show you examples of their work as they attempt to use the new skills until you are convinced they have a more accurate view of the effort they must invest to succeed.

IF students are working in Teams or Collaborative Groups and the group is experiencing performance problems, THEN check the self-efficacy scores of all members and identify students with lower scores and check it against your individual performance evaluation to see if they are investing less effort than others. The low self-efficacy "social loafers" need the low self-efficacy feedback described above.

Scoring and Interpreting the Emotion Questions (Figure 5) and the Attributional Errors Questions (Figure 7) - Reverse score emotions questions 1 and 3.If students indicate strong negative emotions (anger, fear, or depression), meet with them and use the reappraisal Strategy-

IF students have indicated the reason for their problem was uncontrollable by them (Attribution Errors questions 3 and 4)AND/OR they indicate they are very angry, frightened, or depressed (Emotion questions 2, 3, or 5), use the three step Active Listening approach and the Reappraisal Strategy (below):

1. Ask the student to describe what caused their learning problem and listen carefully and nonjudgmentally to their answer;

2. When they finish, succinctly summarize the cause(s) they described back to them - again in a neutral, nonjudgmental way (do not agree or disagree) - and ask, "Did I understand you correctly?"

a. If they say yes, they will often feel less negative emotionally because you have understood and be more willing to discuss solutions so use the Reappraisal Strategy (below step 3).

b. If they say "no," ask them what you misunderstood and repeat step 2 only twice. If they don't think you understand after two attempts, then ask them to think about it and arrange to repeat this active listening and reappraisal strategy the next day.

3. Breathe: Ask them to take three slow, deep breaths to get more oxygen to the brain and calm down a bit so their emotion can be handled and you can help them;

4. Label: Ask them to describe their dominant emotion, for example, "Are you angry or more depressed or mostly frightened?" (in order to decrease the strength of the emotion); and

5. Reappraise (or reattribute): Suggest a less upsetting reason or cause for the event causing their strong emotion (the reason does not have to be accurate or rational to be helpful):

a. Angry students (high score on item 2) are likely to be attributing the cause of their problem to something or someone other than themselves (Check their answer to Reattribution question 2) THEN repeat the cause they told you about and then ask them to consider the possibility that, for example, another person may not have done anything to intentionally cause them a problem or bad thing just happen sometimes and we have to keep moving. Ask if they are "willing to get beyond this and not allow yourself to be defeated because you can succeed at this with a bit more effort." 
b. Depressed students (high score on item 5) they are likely to be taking too much responsibility for causing their own problem (Check their answer to Reattribution Question 2) and so need you to repeat the cause they told you about and then ask them to consider the possibility that "you simply had a bad day or a 'brain cramp' and the problem does not mean there is anything at all wrong with you."Then suggest they only need to work harder on the next challenge and reassure them you know they will succeed and are here to offer help if they need it.

c. Frightened students (high score on item 3) are likely concerned about the future consequence of the problem they experienced and so need your reassurance they will be fine if they simply work harder and stay focused on future assignments and "The only thing to fear in this situation is fear itself because that will cause a self-fulfilling prophecy."If the student appears very anxious, offer to help them with study strategies. Avoid doing their work for them and check to see if they are making progress. 


\section{References}

Ames, D., Maissen, L. B., \& Brockner, J. (2012). The role of listening in interpersonal influence. Journal of Research in Personality, 46. 345-349.

Appleton, J. J., Christenson, S. L., \& Furlong, M. J. (2008). Student engagement with school - Critical conceptual and methodological issues of the construct. Psychology in the Schools, 45(5), 369-386.

Ashford, S., Edmonds, J., \& French, D. (2010). What is the best way to change self-efficacy to promote lifestyle changes and recreational activity? A systematic review with meta-analysis. Health Psychology, 15(2), 265-288.

Bandura, A. (1977). Self-efficacy: Toward a unifying theory of behavioral change. Psychological Review, 84(2), 191-215.

Bandura, A. (1979). Self-referent mechanisms in social learning theory. American Psychologist, 34, 439-441.

Bandura. A, (1997). Self efficacy:The exercise of control. New York: W. H. Freeman.

Bandura, A. (1999). Social cognitive theory of personality. In L. A. Pervin \& O. John (Eds.), Handbook of personality (2nd ed.)(154-196). New York, NY: Guilford Publications.

Bandura, A. (2006). Guide for constructing self-efficacy scales. In F. Pajares \& T. Urdan (Eds.). Selfefficacy beliefs of adolescents (307-337). Charlotte, NC: Information Age Publishing.

Bandura, A., \& Schunk, D. (1981). Cultivating competence, self-efficacy, and intrinsic interest through proximal self-motivation. Journal of Personality and Social Psychology, 41, 586-598.

Boekaerts, M. (1993). Being concerned with well-being and with learning. Educational Psychologist, 28, 149-167.

Bower, G. H. (1995). Emotion and social judgments. [Monograph]. Washington, DC: The Federation of Behavioral, Psychological and Cognitive Sciences (Science and Public Policy Seminars).

Center on Education Policy. (2012). Student motivation - An overlooked piece of school reform. Retrieved from https://files.eric.ed.gov/fulltext/ED532 666.pdf

Clark, R. E. (1999). The CANE model of motivation to learn and to work: A two-stage process of goal commitment and effort. In J. Lowyck, (Ed.), Trends in corporate training. Leuven, Belgium: University of Leuven Press.

Clark, R. E. (2003). Fostering the work motivation of individuals and teams. Performance Improvement, 42(3), 21-29.

Clark, R. E. (2005, January). Five research-tested group motivation strategies. Performance Improvement Journal, 5(1),13-17.

Clark, R. E. (2006a). Motivating individuals, teams and organizations. In J. Pershing (Ed.). Handbook of human performance improvement (3rd ed.), (pp. 268-286). San Francisco: CA: Jossey-Bass Pfeiffer.

Clark, R. E., Howard, K., \& Early, S. (2006b). Motivational challenges experienced in highly complex learning environments. In J. Elen, \& R. E. Clark, (Eds.). Handling complexity in learning environments: Research and theory (pp. 27-43). Oxford, Great Britain: Elsevier Science Ltd.

Cleary, T. J., \& Zimmerman, B. J. (2004). Self-regulation empowerment program: A school-based program to enhance self-regulation and self-motivated cycles of student learning. Psychology in the Schools, 41, 537-550.

Colquitt, J. A., LePine, J. A., \& Noe, R. A. (2000). Toward an integrative theory of training motivation: A meta-analytic path analysis of 20 years of research. Journal of Applied Psychology, 85(5), 678-707.

Condly, S. J. (1999). Motivation to learn and to succeed. A path analysis of the CANE model of cognitive motivation. (Doctoral dissertation, University of Southern California). Retrieved from ProQuest (Accession No. 9955021).

Condly, S., Clark, R. E., \& Stolovitch, H. S. (2003). The effects of incentives on workplace performance: A meta-analytic review of research studies. Performance Improvement Quarterly, 16(3), 46-63.

Corno, L., \& Kanfer, R. (1993). The role of volition in learning and performance. In L. Darling-Hammond (Ed.), Review of Research in Education, 21(1), 301-341. Itasca, IL: F. E. Peacock Publishers.

Dunlosky, J., \& K. A. Rawson. (2015). Practice tests, spaced practice and successive relearning: Tips for classroom use and guiding students' learning. Scholarship of Teaching and Learning in Psychology, 
1(1), 72-78.

Dweck, C. S. (2006). Mindset: The new psychology of success. New York, NY: RandomHouse.

Eccles, J., \& Wigfield, A. (1995). In the mind of the actor: The structure of adolescents' achievement task values and expectancy-related beliefs. Personality and Social Psychology Bulletin, 21, 215-225.

Eccles, J. S., \& Wigfield, A. (2002). Motivational beliefs, values and goals. Annual Review of Psychology 53, 109-132.

Elliot, A. J., Dweck, C. S., \& Yeager, D. S. (2018). Handbook of competence and motivation (2nd ed.). New York: NY: Guilford Press.

Flad, J. (2002). The effects of increasing cognitive load on self report and dual task measures of mental effort on problem solving (Unpublished doctoral dissertation, University of Southern California). Retrieved from ProQuest (Accession No. 3093760).

Forsterling, F. (1985). Attributional retraining: A review. Psychological Bulletin, 98(3), 495-512.

Gimino, A. E. (2000). Factors that influence students' investment of mental effort in academic tasks: A validation and exploratory study (Unpublished doctoral dissertation, University of Southern California). Retrieved from ProQuest (Accession No. 3018083).

Gimino, A. (2002, April). Students' investment of mental effort. Paper presented at the annual meeting of the American Educational Research Association, New Orleans, LA.

Graham S. (1991). A review of attribution theory in achievement contexts. Educational Psychology Review, 3, 5-39

Graham, S., \& Weiner, B. (1996). Theories and principles of motivation. In D. C. Berliner, \& R. C. Calfee (Eds), Handbook of Educational Psychology (pp. 63-84). New York, NY: Routledge.

Hall, N. C., Hladkyj, S., Perry, R. P., \& Ruthig, J. C. (2004). The role of attributional retraining and elaborative learning in college students' academic development. Journal of Social Psychology, 144, 591-612.

Harackiewicz, J. M, Barron, K. E., Pintrich P. R., Elliot A. J., \& Thrash T. M. (2002). Revision of achievement goal theory: Necessary and illuminating. Journal of Educational Psychology, 94, $638-645$

Heckhausen, J., \& Schulz, R. (1995). A life-span theory of control. Psychological Review,102(2), 284-304.

Horowitz, M. J. (2012). Self-identify theory and research methods. Journal of Research Practice, 8(2). Article M14. Retrieved from: http://jrp.icaap.org/index.php/jrp/article/view/296/261

Hull, C. L. (1943). Principles of behavior. New York, NY: Appleton-Century-Crofts.

Immordino-Yang, M. H., \& Damasio, A. (2007). We feel, therefore we learn: The relevance of affective and social neuroscience to education. Mind, Brain and Education, 1(1), 3-10.

Karau, S. J., \& Williams, K. D. (1995). Social loafing: Research findings, implications and future directions. Current Directions in Psychological Science, 4(5), 134-140. doihttp://dx.doi.org/10.11 11/1467-8721.ep10772570

King, P. E., \& Behnke, R. R. (2005). Problems associated with evaluating student performance in groups. College Teaching, 53, 57-61.

Kizibash, A. H., Vanderploeg, R. D., \& Curtiss, G. (2002). The effects of depression and anxiety on memory performance. Archives of Clinical Neuropsychology, 17(1), 57-67.

Kluger, A., \& DiNisi, A. (1998). Feedback interventions: Toward the understanding of a double-edged sword. Current Directions in Psychological Science, 7(3), 67-72.

Lazowski, R. A., \& Hullerman, C. S. (2016). Motivation interventions in education: A meta-analytic review. Review of Educational Research, 86(2), 602-641. doi:https://doi.org /10.3102/0 034654 3156 17832

Lee, J., Bong, M., \& Kim. S. (2014). Interaction between task values and self-efficacy on maladaptive achievement strategy use. Educational Psychology, 34(5), 538-560.

Lepper, M. R., Henderlong, J., \& Gingras, I. (1999). Understanding the effects of extrinsic rewards on intrinsic motivation-Uses and abuses of meta-analysis: Comment on Deci, Koestner, and Ryan (1999). Psychological Bulletin, 125(6), 669-676. 
Locke, E. A., \& Latham, G. P. (2002). Building a practically useful theory of goal setting and task motivation. American Psychologist, 57(9), 705-717.

Martin, A. J., \& Marsh, H. W. (2008). Academic buoyancy: Towards an understanding of students' everyday academic resilience. Journal of School Psychology, 46(1), 53-83.

Mezulis, A. H., Abramson, L. Y., Hyde, J. S., \& Hankin, B. L. (2004). Is there a universal positivity bias in attributions? A meta-analytic review of individual, developmental, and cultural differences in the selfserving attributional bias. Psychological Bulletin, 130(5), 711-747.

Miller, T. M., \& Geraci, L. (2011). Unskilled but aware: Interpreting overconfidence in low performing students. Journal of Experimental Psychology: Learning, Memory and Cognition, 37(2), 502-506.

Moore, D. A.. \& Healy, P. J. (2008). The trouble with overconfidence. Psychological Review, 115(2), 502-517.

Multon, K. D., Brown, S. D., \& Lent, R. W. (1991). Relation of self-efficacy beliefs to academic outcomes: A meta-analytic investigation. Counseling Psychology,38(1), 30-38.

Paas, F., Touvinen, J. E., Tabbers, H., \& Van Gerven, P. W. M. (2003). Cognitive load measures as a means to advance cognitive load theory. Educational Psychologist, 38(1), 63-71.

Paas, F., Touvinen, J. E., van Merrienboër, J. J. G., \& Darabi, A. A. (2006). A motivational perspective on the relation between mental effort and performance: Optimizing learner involvement in instruction. Educational Technology Research and Development, 53(3), 1042-1629.

Pass, F., van Gog, T., \& Sweller, J. (2010). Cognitive load theory: New conceptualizations, specifications and integrated research perspectives. Educational Psychology Review, 22, 115-121.

Perkrun, R. (1993). Facets of adolescents' academic motivation: A longitudinal expectancy-value approach. In P. Pintrich \& M. L. Maehr (Eds.), Advances in motivation and achievement (pp. 139-189). Greenwich, CT: JAI Publishing.

Pekrun, R. (2006). The control-value theory of achievement emotions: Assumptions, corollaries, and implications for educational research and practice. Educational Psychology Review, 18, 315-341.

Pekrun, R., Goetz, T., Titz, W., \& Perry, R. P. (2002). Academic emotions in students' self-regulated learning and achievement: A program of qualitative and quantitative research. Educational Psychologist, 37, 91-106.

Peterson, C., Semmel, A., von Baeyer, C., Abramson, L. Y, Metalsky, G. I., \& Seligman, M. E. P. (1982). The attributional style questionnaire. Cognitive Therapy and Research, 6, 287-299.

Pintrich, P. R. (2003). A motivational science perspective on the role of student motivation in learning and teaching contexts. Journal of Educational Psychology, 95(4), 667-686.

Pintrich, P. R., \& Schunk, D. H. (2002). Motivation in education: Theory, research, and applications (2nd ed.).Englewood Cliffs, $\mathrm{NJ}$ : Prentice Hall.

Plaks, J. E., Grant, H., \& Dweck, C. S. (2005). Violations of implicit theories and the sense of prediction and control: Implications for motivated person perception. Journal of Personality and Social Psychology, 88(2), 245-262.

Reiss, S. (2005). Extrinsic and intrinsic motivation at 30: Unresolved scientific issues The Behavior Analyst, 28(1), 1-14.

Reynolds, J. M. (2003). The role of mathematics anxiety in mathematical motivation: A path analysis of the CANE model. (Doctoral dissertation, University of Central Florida). Retrieved from ProQuest (Accession No. 3081543).

Ryan, R. M., \& Deci, E. L. (2006). Self-regulation and the problem of human autonomy: Does psychology need choice, self-determination, and will? Journal of Personality, 74(6), 1557-1585.

Salomon, G. (1983). The differential investment of mental effort in learning from different sources. Educational Psychologist, 18(1), 42-50.

Saxberg, B. (2015, April 20). Why we need learning engineers. The Chronicle of Higher Education. Retrieved from https://www.chronicle.com/article/Why-We-Need-Learning-Engineers/229391

Schunk, D. H., Meece, J. R., \& Pintrich, P. R. (2014). Motivation in education: Theory, research and applications (4th ed.). New York, NY: Pearson.

Shell, D. F., \& Husman, J. (2008). Control, motivation, affect, and strategic self-regulation in the college classroom: A multidimensional phenomenon. Journal of Educational Psychology, 100(2), 443-459. 
Shute, V. (2008). Focus on formative feedback. Review of Educational Research, 78(1), 153-189.

Snow, R. E. (1996). Aptitude development and education. Psychology, Public Policy and Law,2, $536-560$.

Song, L. J., Pang, G., Peng, K. Z., Law, K. S. Wong, C., \& Chen, Z. (2010). The differential effects of general mental ability and emotional intelligence on academic performance and social interactions. Intelligence, 38(1), 137-143

Steele, C. M. (1997). A threat in the air: How stereotypes shape intellectual identity and performance. American Psychologist, 52(6), 613-629.

Steele, C. M. (2003). Stereotype threat and African-American student achievement. In A. G. Hilliard, T. Perry, \& C. M. Steele (Eds.), Young, gifted, and Black: Promoting high achievement among AfricanAmerican students (pp. 109-130). Boston, MA: Beacon Press.

Steele, C. M., \& Aronson, J. (1995). Stereotype threat and the intellectual test performance of African Americans. Journal of Personality and Social Psychology, 69, 797-811.

Steel, P. (2007). The nature of procrastination: A meta-analytic and theoretical review of quintessential self-regulatory failure. Psychological Bulletin,133(1), 65-94.

Steel, P., Brothen, T., \& Wombach, C. (2001). Procrastination and personality, performance and mood. Personality and Individual Differences, 30, 95-105.

Stone, J., Lynch, C. I., Sjomeling, M., \& Darley, J. M. (1999). Stereotype threat effects on Black and White athletic performance. Journal of Personality and Social Psychology, 77, 1213-1227.

Sweller, J. (1988). Cognitive load during problem solving: Effects on learning. Cognitive Science, 12, 257-285.

Troy, A. S., Shallcross, A. J., \& Mauss, I. B. (2016). A person-by-situation approach to emotion regulation. Psychological Science, 27(3), 423-431.

Um, E., Plass, J. L., Hayward, E. O., \& Homer, B. D. (2012). Emotional design in multimedia learning. Journal of Educational Psychology, 104(2), 485-498.

Van Gog, T, Kirschner, F., Kester, L., \& Paas, F. (2012). Timing and frequency of mental effort measurement: Evidence in favour of repeated measures. Applied Cognitive Psychology, 26(6), 833-839.

Weger, H., Jr., Bell, G. C., Minei, E. M., \& Robinson, M. C. (2014). The relative effectiveness of active listening on initial interactions. International Journal of Listening, 28(1). Retrieved from http://dx.doi. org/10.1080/10904018.2013.813234

Weiner, B. (1986). An attributional theory of motivation and emotion. Psychological Review,92, 548-573.

Weiner, B. (2004). Attribution theory revisited: Transforming cultural purity into theoretical unity. In D. M. Mclnerney, \& S. Van Elten (Eds.), Research on sociocultural influences on motivation and learning (Vol 4)(pp. 13-29). Greenwich, CT: Information Age Publishing.

Weiner, B., \& Kukla, A. (1970). An attributional analysis of achievement motivation. Journal of Personality and Social Psychology, 15(1), 1-20.

Wesley, J. C. (1994). Effects of ability, high school achievement and procrastinatory behavior on college performance. Educational and Psychological Measurement, 54, 404-408.

Wigfield, A., \& Cambria, J. (2010). Students' achievement values, goal orientations, and interest: Definitions, development and relations to achievement outcomes. Developmental Review, 30, 1-35.

Winstone, N. E., Nash, R. A., Parker, M., \& Rowntree, J. (2016). Supporting learners' agentic engagement with feedback: A systematic review and a taxonomy of recipience processes. Educational Psychologist, 52(1), 17-37.

Yeager, D. S., \& Dweck, C. S. (2012). Mindsets that promote resilience: When students believe that personal characteristics can be developed. Educational Psychologist, 47(4), 302-314.

Zimmerman B. J. (2000). Self-efficacy: An essential motive to learn. Contemporary Educational Psychology, 25, 82-91.

Zimmerman, B. J. (2008). Investigating self-regulation and motivation: Historical background, methodological developments, and future prospects. American Educational Research Journal, 45(1), $166-183$. 